\title{
Osteopontin is overexpressed in colorectal carcinoma and is correlated with P53 by immunohistochemistry
}

\author{
JING LI $^{1}$, GUANG-ZHI YANG ${ }^{1}$, ZI-MAN ZHU ${ }^{2}$, ZHI-YONG ZHOU ${ }^{3}$ and LIN LI ${ }^{1}$ \\ ${ }^{1}$ Department of Pathology, the General Hospital of Beijing Military Command, Beijing 100700; \\ ${ }^{2}$ Department of Surgery, The 304th Hospital of PLA, Beijing 100037; \\ ${ }^{3}$ Department of Gastroenterology, The 306th Hospital of PLA, Beijing 100101, P.R. China
}

Received November 4, 2011; Accepted January 17, 2012

DOI: $10.3892 / \mathrm{etm} .2012 .465$

\begin{abstract}
Osteopontin (OPN), a secreted phosphorylated glycoprotein, has been found to be involved in carcinogenesis, progression and metastasis of several types of cancers. The aim of the present study was to investigate the immunohistochemical expression of OPN in colorectal carcinoma (CRC) and its relationship with clinicopathological parameters and P53. Expression of OPN, Ki-67 and TP53 was detected in 77 cases of CRC by immunohistochemistry and the correlation of the expression of OPN with clinicopathological features, Ki-67 and P53 staining was investigated. Thirty-eight cases (49.4\%) of CRC demonstrated OPN overexpression. Overexpression of OPN was associated with lymph node metastasis $(\mathrm{P}=0.025)$ and Dukes' stages $(\mathrm{P}=0.031)$, but not with gender, histological differentiation, depth of tumor invasion, TNM stages or Ki-67 index. The correlation between expression of OPN and TP53 was statistically significant $(\mathrm{P}=0.030)$. In conclusion, $\mathrm{OPN}$ is overexpressed in $\mathrm{CRC}$, and plays a role in tumor progression and metastasis, which is possibly regulated by P53.
\end{abstract}

\section{Introduction}

Colorectal cancer (CRC) is one of the most common malignant neoplasms worldwide. Despite surgical treatment and chemotherapy, the prognosis of CRC remains poor, particularly for patients with metastasis. Although it is believed that alterations of oncogene K-ras, and tumor-suppressor genes, such as P53, APC and DCC, are involved in the pathogenesis, progression and metastasis of $\mathrm{CRC}$, the molecular mechanisms remain unknown.

Osteopontin (OPN) is a secreted phosphorylated glycoprotein which is constitutively expressed in osteoblasts,

Correspondence to: Dr Guang-Zhi Yang, Department of Pathology, The General Hospital of Beijing Military Command, Beijing 100700, P.R. China

E-mail: guangzhiyang@gmail.com

Keywords: colorectal carcinoma,osteopontin,immunohistochemistry, P53 osteoclasts, smooth muscle cells, epithelia of the kidney, lung, stomach and breast, and plays a key role in calcium salt deposit $(1,2)$. It is also involved in inflammation and the immunoreaction process for expression in activated $\mathrm{T}$ lymphocytes and macrophages (3). Recently, cumulative evidence suggests that OPN is overexpressed in several types of carcinomas, such as breast, stomach, lung and liver, and thus is associated with tumor invasion, progression and metastasis (4-8). The mechanisms involved in the up-regulation of OPN in cancers remain unclear, and it is presumed that activation of OPN is controlled by complex regulation pathways due to diverse regulatory sequences in the promoter regions.

As far as CRC is concerned, OPN was identified as a leading marker among the screening of 12,000 genes, and has been correlated with tumorigenesis, invasion and metastasis (8-11). However, to our knowledge immunohistochemistry has only been performed in a few studies, and whether or not OPN plays a role in increasing tumor proliferation has not yet been determined. Furthermore, the tumor-suppressor gene P53, which was suggested to play a role in OPN activation by molecular studies, has not been validated in clinical tissues to date. Thus, in the present study, we examined the expression of OPN protein by immunohistochemistry in CRC and determined its correlation with the proliferation index, clinicopathological characteristics and P53.

\section{Materials and methods}

Tissue specimens. Tissue samples were obtained by surgical resection from 77 patients (36 males and 41 females; age 27-87 years, mean 60) with CRC in our department between 2006 and 2009; none of whom had received irradiation or chemotherapy prior to surgery. The study was approved by the local ethics committees. The cases were histologically confirmed by two experienced pathologists, respectively. Normal colorectal tissues for each case were obtained $\sim 5 \mathrm{~cm}$ away from the tumors, which were also confirmed by histology.

Antibodies. Rabbit polyclonal antibody against human OPN and mouse monoclonal antibodies against $\mathrm{Ki}-67$ and P53 (clone nos. MIB-1 and DO-7, respectively) were purchased from Maxin-Bio Corp. (Fuzhou, China). 


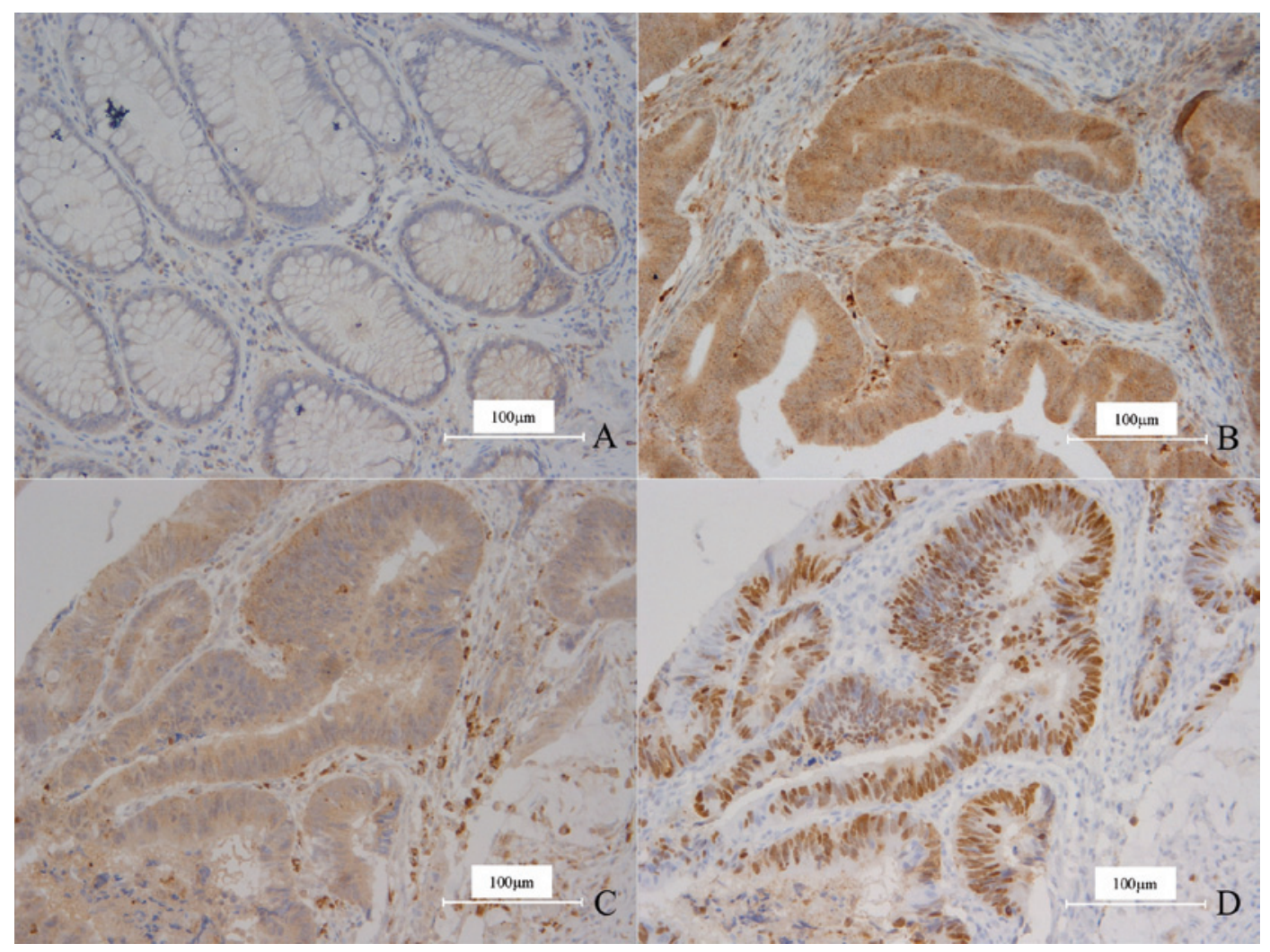

Figure 1. (A) OPN was weakly expressed in the cytoplasm of a small number of normal gland epithelial cells. (B) OPN was intensely expressed in the cytoplasm of the carcinoma cells in CRC. Surrounding macrophages exhibited strong positivity. OPN and P53 were positive in the same field of the carcinoma cells in CRC in (C) and (D). (C) Intense staining of OPN. (D) Diffuse staining of P53. Magnification, x200.

Immunohistochemistry. Immunohistochemistry was performed on formalin-fixed, paraffin-embedded tissue sections using the Envision peroxidase detection method. Sections $(4-\mu \mathrm{m})$ were deparaffinized in xylene, dehydrated through graded ethanols and subsequently treated with $0.3 \%$ hydrogen peroxide in methanol for $30 \mathrm{~min}$ at room temperature to eliminate the endogenous peroxidase activity. For antigen retrieval, the sections were microwaved in $10 \mathrm{mM}$ citrate buffer ( $\mathrm{pH}$ 6.0) for $10 \mathrm{~min}$. The primary antibodies were incubated overnight at $4^{\circ} \mathrm{C}$ after blocking non-specific binding with $10 \%$ normal goat serum in PBS for $30 \mathrm{~min}$. For negative controls, PBS was used as substitutes for the primary antibodies. Sections were incubated with Envision peroxidase complex for $20 \mathrm{~min}$. Sections were counterstained with Mayer's hematoxylin after immunostaining prior to mounting.

Evaluation of OPN, Ki-67 and P53 immunostaining. All sections were evaluated without knowledge of the clinical and pathological background of the patients. Unambiguous yellow staining of the cytoplasm was regarded as OPN-positive, and nuclear staining as Ki-67- and P53-positive. The expression of OPN and P53 was determined in each case when positive cells were $>10 \%$, since the positive pattern was often diffuse and similar in staining intensity. For Ki-67, the index was classified into three groups according to the positive cell ratio; the low index group was indicated when positive cells were $<50 \%$, high index when positive cells were $>75 \%$ and intermediate index was indicated between the high and low range.

Statistical analysis. Statistical analysis was performed using SPSS software with the $\chi^{2}$ test. All statistical significance tests were two-tailed and significance was established at $\mathrm{P}<0.05$.

\section{Results}

In either normal or carcinoma tissue, OPN was expressed in smooth muscle cells and macrophages, which were thus used as the inner positive control. In normal colorectal gland epithelia, OPN only displayed weak staining in a few cells and the ratios were much $<10 \%$, therefore all the cases were determined as negative (Fig. 1A).

Thirty-eight cases (49.4\%) of CRC demonstrated OPN overexpression (Fig. 1B), and compared to the normal tissues, the difference was significant $\left(\chi^{2}=50.448, \mathrm{P}=0.000\right)$. The staining pattern of OPN was quite diffuse and homogeneous; the intensity of the positive carcinoma cells was almost identical wherever the cells were located. In detail, the cells on the centers or borders of the carcinoma nests, even in the invading fronts, displayed no difference from the other cells.

Overexpression of OPN was not significantly correlated with gender, histological differentiation, invasion depth and TNM stages. However, it was associated with lymph node metastasis $\left(\chi^{2}=7.355, P=0.025\right)$, which indicated that OPN expression was higher in carcinomas with metastases. It was 
Table I. Immunohistochemical expression of OPN and its relationship with clinicopathological parameters of the CRC patients.

\begin{tabular}{|c|c|c|c|}
\hline & \multicolumn{2}{|c|}{ OPN expression, n (\%) } & \multirow[t]{2}{*}{ P-value } \\
\hline & Positive & Negative & \\
\hline Gender & & & 0.573 \\
\hline Male & $19(24.7)$ & $17(22.1)$ & \\
\hline Female & $19(24.7)$ & $22(28.5)$ & \\
\hline Degree of differentiation & & & 0.982 \\
\hline Well & $9(11.7)$ & $11(14.3)$ & \\
\hline Moderate & $15(19.5)$ & $22(28.6)$ & \\
\hline Poor & $14(18.2)$ & $6 \quad(7.7)$ & \\
\hline Depth of invasion & & & 0.854 \\
\hline $\mathrm{T} 1$ & $1 \quad(1.3)$ & $2(2.5)$ & \\
\hline $\mathrm{T} 2$ & $9(11.7)$ & $9(11.7)$ & \\
\hline $\mathrm{T} 3$ & $28(36.4)$ & $28(36.4)$ & \\
\hline Metastasis & & & 0.025 \\
\hline N0 & $16(20.8)$ & $28(36.4)$ & \\
\hline N1 & $15(19.5)$ & $6(7.8)$ & \\
\hline $\mathrm{N} 2$ & $7 \quad(9.1)$ & $5 \quad(6.4)$ & \\
\hline TNM stage & & & 0.111 \\
\hline I & $6 \quad(7.8)$ & $9(11.7)$ & \\
\hline II & $10(13.0)$ & $19(24.7)$ & \\
\hline IIIA & $2(2.6)$ & $1 \quad(1.3)$ & \\
\hline IIIB & $13(16.9)$ & $5 \quad(6.5)$ & \\
\hline IIIC & $7 \quad(9.1)$ & $5 \quad(6.5)$ & \\
\hline Dukes' stage & & & 0.031 \\
\hline A & $6 \quad(7.8)$ & $9(11.7)$ & \\
\hline B & $10(13.0)$ & $19(24.7)$ & \\
\hline $\mathrm{C}$ & $22(28.6)$ & $11(14.2)$ & \\
\hline Ki-67 index & & & 0.770 \\
\hline Low & $4 \quad(5.2)$ & $6 \quad(7.8)$ & \\
\hline Moderate & $15(19.5)$ & $16(20.7)$ & \\
\hline High & $19(24.7)$ & $17(22.1)$ & \\
\hline
\end{tabular}

Table II. Correlation between OPN and P53 immunostaining.

\begin{tabular}{lrc}
\hline OPN expression & \multicolumn{2}{c}{ P53 } \\
\cline { 2 - 3 } & Positive & Negative \\
\hline Positive & 31 & 23 \\
Negative & 7 & 16 \\
\hline
\end{tabular}

also correlated with Dukes' stages, thus OPN expression increased with advanced clinical stage $\left(\chi^{2}=7.789, \mathrm{P}=0.031\right)$. As far as the proliferation or MIB-1 index of the carcinomas was concerned, expression of OPN remained unchanged. The relationship between the expression of OPN and clinicopathological parameters is summarized in Table I.

The expression of P53 was noted in 54 cases $(70.1 \%)$, and a statistical correlation between the expression of OPN and P53 was found $\left(\chi^{2}=4.695, P=0.030\right.$; Fig. $1 C$ and D; Table II).

\section{Discussion}

OPN was initially proven to play a key role in calcium salt deposit, inflammation and immunoreaction process, yet further evidence suggests that OPN contributes to the tumorigenesis, progression and metastasis of many types of malignant neoplasms, such as breast, stomach, lung, prostate and liver carcinoma.

Numerous studies have investigated the association between OPN and CRC. Most strikingly, the screening of pooled sample expression profiles among 12,000 human genes identified OPN as a leading marker of colon cancer progression (9). In subsequent studies, overexpression of OPN was confirmed in CRC by northern blotting, PCR or immunohistochemistry. To date, an association between the up-regulation of OPN and tumor progression has been demonstrated, and it was determined as an independent prognostic factor in multivariate regression analysis. Notably, the role of OPN in metastasis has been intensively researched since its expression was not only reserved, but was also increased in metastases $(9,12,13)$.

In the present study, we further confirmed that OPN is overexpressed in CRC and is associated with tumor stage and lymph node metastasis by immunostaining, thereby relating it to tumor progression and metastasis. The expression of OPN was associated with Dukes' stages, but not with TNM stages in our results. The small number of samples in some stages, such as I and IIIa, was rebuked resulting in some degree of statistical bias.

In previous studies, OPN was verified to be involved in tumorigenesis, thus it seemed rational that OPN may promote tumor proliferation. Ki-67 (MIB-1) recognizes all cells throughout the cell cycle, except for $\mathrm{G}_{0}$ stage, and well reflects cell proliferation. Ki-67 has been widely used in neoplasms to estimate malignancy and prognosis. However, in our study the possibility that OPN regulates CRC cell proliferation was not confirmed. Therefore, it is speculated that other mechanisms exist to explain the involvement of OPN in tumorigenesis, such as facilitation of cell transformation or prevention of apoptosis.

It is believed that the involvement of OPN in malignancy is due to its biological functions and several activating downstream signal pathways. OPN mainly functions on cell-matrix interactions through binding and activating relevant ligands with certain surface structure domains. It has been widely accepted that overexpressed OPN in tumors ligates with and activates $\alpha_{\mathrm{v}} \beta$ integrins or CD44 (14-17). Data already indicate that $\alpha_{\mathrm{v}} \beta$ integrins and CD44 may contribute to carcinogenesis, progression or metastasis through promoting cell transformation, migration, adhesion to extracellular matrix, neovascularization and immune suppression. Thus, OPN functions between tumor cells and mesenchyme mainly through such exterior molecules. On the other hand, binding of OPN may also activate several inner downstream signaling pathways, such as phosphatidylinositol 3-kinase/protein kinase $\mathrm{B}$, nuclear factor- $\kappa \mathrm{B}$ and urokinase plasminogen, which were also proven to be involved in tumors (18-20).

Although the mechanisms regulating the expression of OPN remain unknown, a variety of cisacting elements in the promoter region, including TATA-box and CCAAT-box, 
suggests, that it is controlled by complex regulatory pathways (21). The Wnt pathway is proven to be activated in CRC, and immunostaining analysis also indicates that increased OPN expression is significantly correlated with elevated nuclear and cytoplasmic $\beta$-catenin staining, which is a central component of the Wnt signaling pathway. It has been concluded that overexpression of OPN is regulated by the Wnt pathway, at least in part. However, OPN was found to be expressed more frequently than $\beta$-catenin in CRC, so it was presumed that other pathways are involved in the regulation of OPN (10). Tumor-suppressor gene P53, which plays a critical role in cell-cycle regulation, apoptosis and immunosurveillance, has a role in many types of tumors, including CRC. Morimoto et al (22) found that induction of OPN expression by P53 is conserved across multiple species, and the endogenous OPN gene was induced in mouse and rat embryo fibroblasts in a P53-dependent manner. OPN was also induced in the A172 human glioblastoma cell line in P53-associated activities. In addition, a potential P53 responsive element, ctGCT TGCTT AGGCgAGCTC, located approximately $1 \mathrm{~kb}$ upstream of the first exon sequence, which contains only three-mismatch nucleotides in the non-critical position compared to the consensus P53-binding sequence, was found in the OPN gene promoter and confirmed by chromatin immunoprecipitation assay in the HCT116 human CRC cell line (21). These results suggest that the OPN gene is a direct target of transcription activation by P53. In our immunohistochemical study, we demonstrated that expression of P53 was significantly correlated with OPN, which is an indirect proof of P53-regulated OPN expression.

Recent studies suggest that OPN and related molecules are a potential target for anticancer therapy. In addition, the plasma concentration of OPN in patients with tumor metastasis is significantly increased in comparison to normal sera, thus its prospects as a marker for evaluating tumor genesis and metastasis are expected (22-24). Accordingly, further research on OPN is warranted.

In summary, the present study provides immunohistochemical evidence that OPN is overexpressed in CRC and is related to tumor progression and lymph node metastasis supposedly regulated by P53.

\section{References}

1. Denhardt DT and Noda M: Osteopontin expression and function: role in bone remodeling. J Cell Biochem Suppl 30-31: 92-102, 1998.

2. Denhardt DT and Guo X: Osteopontin: a protein with diverse functions. FASEB J 7: 1475-1482, 1993.

3. Lund SA, Giachelli CM and Scatena M: The role of osteopontin in inflammatory processes. J Cell Commun Signal 3: 311-322, 2009.

4. Patani N, Jouhra F, Jiang W and Mokbel K: Osteopontin expression profiles predict pathological and clinical outcome in breast cancer. Anticancer Res 28: 4105-4110, 2008.

5. Higashiyama M, Ito T, Tanaka E and Shimada Y: Prognostic significance of osteopontin expression in human gastric carcinoma. Ann Surg Oncol 14: 3419-3127, 2007.

6. Weber GF, Lett GS and Haubein NC: Osteopontin is a marker for cancer aggressiveness and patient survival. Br J Cancer 103: $861-869,2010$.

7. Korita PV, Wakai T, Shirai Y, Matsuda Y, Sakata J, Cui X, Ajioka Y and Hatakeyama K: Overexpression of osteopontin independently correlates with vascular invasion and poor prognosis in patients with hepatocellular carcinoma. Hum Pathol 39: 1777-1783, 2008.
8. Coppola D, Szabo M, Boulware D, Muraca P, Alsarraj M, Chambers AF and Yeatman TJ: Correlation of osteopontin protein expression and pathological stage across a wide variety of tumor histologies. Clin Cancer Res 10: 184-190, 2004.

9. Agrawal D, Chen T, Irby R, Quackenbush J, Chambers AF, Szabo M, Cantor A, Coppola D and Yeatman TJ: Osteopontin identified as lead marker of colon cancer progression, using pooled sample expression profiling. J Natl Cancer Inst 94: 513-521, 2002.

10. Rohde F, Rimkus C, Friederichs J, Rosenberg R, Marthen C, Doll D, Holzmann B, Siewert JR and Janssen KP: Expression of osteopontin, a target gene of de-regulated Wnt signaling, predicts survival in colon cancer. Int J Cancer 21: 1717-1723, 2007.

11. Allan AL, George R, Vantyghem SA, Lee MW, Hodgson NC, Engel CJ, Holliday RL, Girvan DP, Scott LA, Postenka CO, et al: Role of the integrin-binding protein osteopontin in lymphatic metastasis of breast cancer. Am J Pathol 169: 233-246, 2006.

12. Carlinfante G, Vassiliou D, Svensson O, Wendel M, Heinegård D and Andersson G: Differential expression of osteopontin and bone sialoprotein in bone metastasis of breast and prostate carcinoma. Clin Exp Metastasis 20: 437-444, 2003.

13. Irby RB, McCarthy SM and Yeatman TJ: Osteopontin regulates multiple functions contributing to human colon cancer development and progression. Clin Exp Metastasis 21: 515-523, 2004.

14. Wai PY and Kuo PC: Osteopontin: regulation in tumor metastasis. Cancer Metastasis Rev 27: 103-118, 2008.

15. Leali D, Moroni E, Bussolino F and Presta M: Osteopontin overexpression inhibits in vitro re-endothelialization via integrin engagement. J Biol Chem 282: 19676-19684, 2007.

16. Anborgh PH, Mutrie JC, Tuck AB and Chambers AF: Role of the metastasis-promoting protein osteopontin in the tumour microenvironment. J Cell Mol Med 14: 2037-2044, 2010.

17. Hsu KH, Tsai HW, Lin PW, Hsu YS, Shan YS and Lu PJ: Osteopontin expression is an independent adverse prognostic factor in resectable gastrointestinal stromal tumor and its interaction with CD44 promotes tumor proliferation. Ann Surg Oncol 17: 3043-3052, 2010.

18. Dai J, Peng L, Fan K, Wang H, Wei R, Ji G, Cai J, Lu B, Li B, Zhang D, Kang Y, Tan M, Qian W and Guo Y: Osteopontin induces angiogenesis through activation of PI3K/AKT and ERK1/2 in endothelial cells. Oncogene 28: 3412-3422, 2009.

19. Fong YC, Liu SC, Huang CY, Li TM, Hsu SF, Kao ST, Tsai FJ, Chen WC, Chen CY and Tang CH: Osteopontin increases lung cancer cells migration via activation of the alphavbeta3 integrin/ FAK/Akt and NF-kappaB-dependent pathway. Lung Cancer 64: 263-270, 2009.

20. Tuck AB, Hota C and Chambers AF: Osteopontin (OPN)induced increase in human mammary epithelial cell invasiveness is urokinase (uPA)-dependent. Breast Cancer Res Treat 70: $197-204,2001$.

21. Hijiya N, Setoguchi M, Matsuura K, Higuchi Y, Akizuki S and Yamamoto S: Cloning and characterization of the human osteopontin gene and its promoter. Biochem J 303: 255-262, 1994.

22. Morimoto I, Sasaki Y, Ishida S, Imai K and Tokino T: Identification of the osteopontin gene as a direct target of TP53. Genes Chromosomes Cancer 33: 270-278, 2002.

23. Cristaudo A, Foddis R, Bonotti A, Simonini S, Vivaldi A, Guglielmi G, Ambrosino N, Canessa PA, Chella A, Lucchi M, Mussi A and Mutti L: Comparison between plasma and serum osteopontin levels: usefulness in diagnosis of epithelial malignant pleural mesothelioma. Int J Biol Markers 25: 164-170, 2010.

24. Sreekanthreddy P, Srinivasan H, Kumar DM, Nijaguna MB, Sridevi S, Vrinda M, Arivazhagan A, Balasubramaniam A, Hegde AS, Chandramouli BA, et al: Identification of potential serum biomarkers of glioblastoma: serum osteopontin levels correlate with poor prognosis. Cancer Epidemiol Biomarkers Prev 19: 1409-1422, 2010.

25. Isa S, Kawaguchi T, Teramukai S, Minato K, Ohsaki Y, Shibata K, Yonei T, Hayashibara K, Fukushima M, Kawahara M, Furuse K and Mack PC: Serum osteopontin levels are highly prognostic for survival in advanced non-small cell lung cancer: results from JMTO LC 0004. J Thorac Oncol 4: 1104-1110, 2009. 